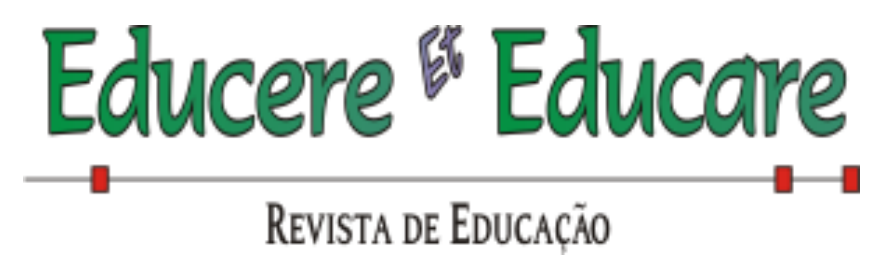

Programa de Pós-Graduação em Educação - Universidade Estadual do Oeste do Paraná

\title{
A FORMAÇÃO INICIAL DO PROFESSOR ALFABETIZADOR NO CURSO DE PEDAGOGIA DA UFS: DA TEORIA À PRÁTICA
}

\author{
Vitória Karolina Costa Freitas 0000-0002-7026-7945 \\ Dra. Verônica dos Reis Mariano Souza 0000-0001-8076-098X \\ Dra. Priscila Dantas Fernandes 0000-0002-9501-9200 \\ Universidade Federal de Sergipe
}

RESUMO: Neste trabalho analisamos a relação entre a teoria e a prática na formação em Alfabetização de alunos concludentes do Curso de Pedagogia da Universidade Federal de Sergipe (UFS) e de professores do Ensino Fundamental de uma escola pública localizada no município de São Cristóvão (SE). Realizamos uma pesquisa descritiva mediante observação participante e aplicação de questionários. A alfabetização se configura como componente basilar na formação inicial de professores para atuação com crianças, jovens e adultos. Aferimos que a formação inicial do Curso de Pedagogia da UFS estabelecia relação direta dos fundamentos teóricos da Alfabetização com a prática escolar e percebemos também que há uma necessidade de haver mais disciplinas relacionadas ao processo de Alfabetização, tendo em vista que só há duas.

PALAVRAS-CHAVE: Alfabetização; Prática; Teoria.

\section{THE INITIAL TRAINING OF THE LITERACY TEACHER IN THE UFS PEDAGOGY COURSE: FROM THEORY TO PRACTICE}

\begin{abstract}
In this work we analyze the relationship between theory and practice in Literacy training for students who completed the Pedagogy Course at the Federal University of Sergipe (UFS) and teachers of elementary school at a public school located in the city of São Cristóvão (SE). We conducted a descriptive research through participant observation and questionnaires. Literacy is configured as a basic
\end{abstract}

component in the initial training of teachers to work with children, youth and adults.

We found that the initial formation of the UFS Pedagogy Course established a direct relationship between the theoretical foundations of Literacy and school practice and we also realized that there is a need for more disciplines related to the Literacy process, considering that there are only two.

KEYWORDS: Literacy; Practice; Theory.

Revista Educere Et Educare, Vol. 15, N. 36 (2020) Especial Educere, Out. 2020. Ahead of Print. DOI: $10.17648 /$ educare.v15i36.25716 


\section{Educere "Educare \\ ReVISTA DE EduCACÃ̃o \\ Programa de Pós-Graduação em Educação - Universidade Estadual do Oeste do Paraná}

\section{INTRODUÇÃO}

A alfabetização é um tema bastante estudado e problematizado, mas mal resolvido no Brasil. Conforme Diogo e Gorette (2011, p. 12193, apud MORTATTI, 2006), "na história do Brasil, a alfabetização ganha força, principalmente, após a Proclamação da República, com a institucionalização da escola e com o intuito de tornar as novas gerações aptas à nova ordem política e social”. Os avanços nas diferentes áreas de estudos na aprendizagem da língua escrita, contribuem para melhorar a forma como se é ensinado. Muito se tem abordado que a causa para a baixa qualidade de aprendizado seriam os métodos e até mesmo o professor.

Sabemos que diferentes aspectos contribuem para o fracasso na alfabetização, dentre eles: acompanhamento, incentivo, valorização familiar na educação dos alunos; desestruturação da família; desinteresse e desmotivação dos professores; desvalorização profissional; problemas estruturais e de infraestrutura nas escolas; questões socioeconômicas; má gestão; práticas pedagógicas conservadoras; evasão escolar; elevado quantitativo de alunos em sala de aula.

Consideramos fundamental que o professor tenha dominio das teorias que abordam os processos de aprendizagem e quais os caminhos de alfabetização que poderão trilhar junto com os alunos. Segundo Morais et al (2012, p. 10),

[...] é importante que a criança tenha oportunidade de refletir sobre o sistema de escritas alfabética, podendo, de fato, compreender como este sistema funciona. Por mais que elas sejam colocadas em contato com diferentes tipos de texto, dificilmente se apropriarão espontaneamente da língua escrita e de suas características. Assim, é preciso conjugar ambos os aspectos numa prática educativa contextualizada e sistemática de ensino do sistema de escritas, assumindo a proposição de se alfabetizar letrando, concomitantemente.

Além disso, cabe ao professor mostrar os caminhos que poderão ajudar seus alunos a adquirirem a habilidade de leitura e escrita. Como um professor pretende realizar um bom trabalho sem uma base teórica que o fundamente e que dê suportes necessários para isso? O professor precisa ter consciência da 


\section{Educere "Educare \\ ReVISTA DE EduCAČ̃̃o}

Programa de Pós-Graduação em Educação - Universidade Estadual do Oeste do Paraná

importância e da necessidade de seu trabalho, ou seja, "[...] um professor que não sabe alfabetizar, não fez bom proveito das disciplinas relacionadas ao processo de alfabetização e letramento, como também não fez bom proveito do seu Curso, pois isso é a base" (SOUZA, 2019).

As avaliações nacionais e internacionais evidenciam o baixo índice do ensino no Brasil, dentre elas, destacamos a Avaliação Nacional de Alfabetização ANA (2006) demonstrando que $54,7 \%$ das crianças brasileiras do $3^{\circ}$ ano do Ensino Fundamental - Anos Iniciais possuem niveis insuficientes de leitura. Em Sergipe, temos o lamentável índice no qual mais de $80 \%$ não conseguem ler e menos de $20 \%$ das crianças chegam ao $3^{\circ}$ ano do Ensino Fundamental - Anos Iniciais com proficiência em leitura. Diante disso, consideramos as questões de alfabetização como um grave problema.

Nesse sentido, o presente texto tem como objetivo analisar a relação entre a teoria e a prática na formação em Alfabetização de alunos concludentes do Curso de Pedagogia da UFS e de professores do Ensino Fundamental de uma escola pública localizada no município de São Cristóvão (SE). Embasamo-nos teoricamente em Abramovich (2001), Antunes (2013), Brito (2007), Cagliari (2009), Colello (2001), Diogo e Gorette (2011), Soares (2012; 2018), dentre outros.

\section{TEORIA E PRÁTICA DO ALFABETIZADOR: A FORMAÇÃO EM QUESTÃO}

A formação do professor alfabetizador inicia-se no Curso de Pedagogia em que "cabe estudar, conhecer e explicar os diferentes modos de como a Educação se manifesta, historicamente, como prática social” (GOMES; LIMA, 2005, p. 170). A Lei de Diretrizes e Bases da Educação (LDB) no 9.394/96, assegura que para atuar na educação básica, a formação docente deverá ocorrer em curso de licenciatura plena, admitida, como formação mínima para o exercício do

Revista Educere Et Educare, Vol. 15, N. 36 (2020) Especial Educere, Out. 2020. Ahead of Print. DOI: $10.17648 /$ educare.v15i36.25716 


\section{Educere "Educare \\ ReVISTA DE EduCAČ̃̃o}

Programa de Pós-Graduação em Educação - Universidade Estadual do Oeste do Paraná

magistério na educação infantil e nos cinco primeiros anos do ensino fundamental, a oferecida em nível médio, na modalidade normal (BRASIL, 1996).

As Diretrizes Curriculares Nacionais para o Curso de Graduação em Pedagogia, licenciatura (2006) aplicam-se à formação inicial para o exercício da docência na educação infantil e nos anos iniciais do ensino fundamental, nos cursos de ensino médio, na modalidade normal, e em cursos de educação profissional. Relacionam a docência como "ação educativa e processo pedagógico metódico e intencional, construído em relações sociais, étnico-raciais e produtivas", e direcionam o Curso de Pedagogia ao "planejamento, execução e avaliação de atividades educativas, por meio de estudos teórico-práticos, investigação e reflexão crítica". Sendo assim, a teoria fornecida nessa Licenciatura caracteriza-se como a base do profissional pedagogo e complementada na prática, momento em que fará a relação entre a teoria e a prática aperfeiçoando-a de acordo com a sua realidade.

As Diretrizes Curriculares Nacionais para a Formação Inicial e Continuada dos Profissionais do Magistério da Educação Básica (2015), determinam que para exercerem atividades de docência e demais atividades pedagógicas, os professores podem lecionar na educação infantil, no ensino fundamental, no ensino médio e nas respectivas modalidades de educação (Educação de Jovens e Adultos, Educação Especial, Educação Profissional e Tecnológica, Educação do Campo, Educação Escolar Indígena, Educação a Distância e Educação Escolar Quilombola). As DCN (2015) afirmam que o egresso do Curso de Pedagogia deve "trabalhar na promoção da aprendizagem e do desenvolvimento de sujeitos em diferentes fases do desenvolvimento humano nas etapas e modalidades de educação básica". Nesse sentido, uma das etapas mais importantes na vida escolar de uma criança é a alfabetização, período em que provavelmente haverá a aquisição sistemática da leitura e da escrita.

Os conhecimentos adquiridos durante a formação inicial de professor, notadamente de Pedagogia, através da teoria e prática, são respaldados nas

Revista Educere Et Educare, Vol. 15, N. 36 (2020) Especial Educere, Out. 2020. Ahead of Print. DOI: $10.17648 /$ educare.v15i36.25716 


\section{Educere Educare}

RevisTA De EduCAC̄̃̃o

Programa de Pós-Graduação em Educação - Universidade Estadual do Oeste do Paraná

diretrizes. De acordo com as DCN (2015), no processo de formação docente deve existir "a articulação entre a teoria e a prática [...], fundada no domínio dos conhecimentos científicos e didáticos, contemplando a indissociabilidade entre ensino, pesquisa e extensão". Os cursos de formação deverão garantir nos currículos conteúdos específicos da respectiva área de conhecimento, os fundamentos da educação, formação na área de políticas públicas e gestão da educação, direitos humanos, diversidades étnico-racial, de gênero, sexual, religiosa, Língua Brasileira de Sinais (Libras), educação especial e direitos educacionais de adolescentes e jovens em cumprimento de medidas socioeducativas (DCN, 2015).

Nessa perspectiva, todos os aportes legais elencados anteriormente subsidiam a formação inicial do professor alfabetizador. Para Freire (1996, p. 92), "o professor que não leve a sério sua formação, que não estude, que não se esforce para estar à altura de sua tarefa não tem força moral para coordenar as atividades de sua classe". São grandes os desafios do processo de alfabetizar de maneira competente, respondendo às expectativas de aquisição da leitura e da escrita relacionadas aos usos e funções sociais em uma sociedade letrada. Por isso, a formação teórica e a prática de professores em sala de aula são alvos de discussão entre profissionais e pesquisadores da área da Educação.

A relação teoria-prática é um requisito básico para a formação do professor, realizada por meio do estudo, da pesquisa, da reflexão e do constante contato com novas concepções de ensino-aprendizagem. É mais difícil que o professor mude seu modo de pensar e seu fazer pedagógico se ele não tiver a oportunidade de vivenciar novas experiências, novas pesquisas, novas formas de ver e pensar a escola (FERNANDES; SOUZA, 2019).

O ensino da alfabetização é uma tarefa complexa e com especificidades. Segundo Nóvoa (1995, p. 78), "mais do que os vários outros tipos de professores, os alfabetizadores precisam de uma formação especial, mais sólida e sofisticada, dada a importância e a complexidade de seu trabalho". Além de todos os

Revista Educere Et Educare, Vol. 15, N. 36 (2020) Especial Educere, Out. 2020. Ahead of Print. DOI: $10.17648 /$ educare.v15i36.25716 


\section{Educere "Educare \\ ReVISTA DE EduCAČ̃̃o}

Programa de Pós-Graduação em Educação - Universidade Estadual do Oeste do Paraná

fundamentos teóricos e práticos específicos da formação para o Magistério, o professor alfabetizador precisa conhecer a língua que ensina, uma vez que é um "profissional do ensino de línguas e, como tal, além do domínio e das técnicas pedagógicas deve possuir sólidos conhecimentos linguísticos tanto da língua, enquanto meio de comunicação, quanto sobre a língua, enquanto objeto de análise" (POERSCH, 1990, p. 37).

É fundamental que o professor alfabetizador obtenha uma compreensão sobre a língua e, as práticas de oralidade, leitura e escrita que compõem o ensino na alfabetização. Ministrar as aulas a partir das funções sociais da escrita na sociedade e levando em consideração a amplitude e a complexidade da alfabetização é fundamental, tendo em vista que suas vivências de mundo não devem ser descartadas, mas sim exploradas em sala de aula para que o processo de alfabetização alcance bons resultados.

O caminho percorrido para a alfabetização apresenta contextos em que são desenvolvidas relações entre diversas ciências, e isso faz com que a criança amplie seu aprendizado de forma mais compreensivel, pois o conhecimento adquirido tem relação com situações do seu cotidiano. Os professores devem articular e ampliar as experiências vividas pelas crianças por meio de novos conhecimentos através de práticas pedagógicas alfabetizadoras oportunizando a leitura e a escrita com qualidade (VIRAGO, 2014).

Observar o ambiente que a criança vive e o que ela tem a dizer é determinante para o sucesso ou insucesso da alfabetização, já que, os aspectos sociais, culturais, econômicos e políticos influenciam no processo de aquisição da língua escrita. A escola precisa intensificar as oportunidades dos usos sociais da escrita no cotidiano da alfabetização, uma vez há uma disparidade social quanto ao acesso à leitura daqueles que desde cedo mantêm o contato com livros, revista e jornais. Assim, para alfabetizar o educador precisa motivar o educando a enveredar-se pelo mundo da escrita, descobrindo o que os motiva, suas necessidades e anseios.

Revista Educere Et Educare, Vol. 15, N. 36 (2020) Especial Educere, Out. 2020. Ahead of Print. DOI: $10.17648 /$ educare.v15i36.25716 


\section{Educere "Educare \\ ReVISTA DE EduCACÃ̃o \\ Programa de Pós-Graduação em Educação - Universidade Estadual do Oeste do Paraná}

\section{METODOLOGIA}

Almejamos, como procedimento metodológico, analisar a realidade completa, interpretando os sentidos e as significações dos fenômenos que ocorreram durante a pesquisa, através das técnicas. Tratou-se de uma pesquisa descritiva e segundo Triviños (2009, p. 110).

A maioria dos estudos que se realizam no campo da educação é de natureza descritiva. O foco essencial destes estudos reside no desejo de conhecer a comunidade, seus traços característicos, suas gentes, seus problemas, suas escolas, seus professores, sua educação, sua preparação para o trabalho, seus valores, os problemas do analfabetismo, a desnutrição, as reformas curriculares, os métodos de ensino, o mercado ocupacional, os problemas do adolescente etc. Os estudos descritivos exigem do pesquisador uma série de informações sobre o que se deseja pesquisar.

A pesquisa consistiu em quatro etapas: levantamento bibliográfico, observação participante, questionários e diálogos informais e, sistematização e análise dos dados. Desenvolvemos o estudo em uma escola pública municipal de Ensino Fundamental localizada no município de São Cristóvão (SE). Efetuamos a observação em uma turma de $3^{\circ}$ ano do Ensino Fundamental numa escola pública, no período de 25 de setembro de 2019 a 02 de dezembro de 2019, onde haviam 35 alunos. Desta turma, selecionamos 12 alunos em fase de alfabetização com idade entre 08 e 12 anos que apresentavam maiores dificuldades de leitura e escrita.

A observação participante consistiu em desenvolvermos nas crianças a relação dos sons da fala com as respectivas letras, tomando como base que para aprender a ler e a escrever, é necessário que "[...] o aprendiz volte sua atenção para os sons da fala, e tome consciência das relações entre eles e sua representação gráfica, tanto no nível da palavra quanto no nivel das relações fonema-grafema" (SOARES, 2018, p. 124).

Revista Educere Et Educare, Vol. 15, N. 36 (2020) Especial Educere, Out. 2020. Ahead of Print. DOI: $10.17648 /$ educare.v15i36.25716 


\section{Educere Educare \\ ReVISTA DE EduCACÃ̃o}

Programa de Pós-Graduação em Educação - Universidade Estadual do Oeste do Paraná

A estrutura da escola era muita favorável ao aprendizado, com salas de aula climatizadas e em ótimo estado de conservação; diversos materiais lúdicos e educativos para as crianças; muitos livros de histórias infantis. A professora da sala, onde fizemos a observação, foi bastante receptiva e nos permitiu participar das práticas nas aulas.

Com isso, pudemos verificar as práticas da professora em sala de aula e perceber a realidade dos educandos para que contribuíssemos nas atividades através das técnicas e procedimentos adquiridos nas disciplinas do Curso de Pedagogia da UFS, como também por meio dos estudos realizados mediante o levantamento bibliográfico. Além disso, a prática nos permitiu levar em consideração os conhecimentos prévios que os alunos possuíam, uma vez que" é importante que os professores façam um diagnóstico do conhecimento de seus alunos, para saberem de onde devem partir e planejar suas atividades (DIOGO; GORETTE, 2011, p. 12198).

Durante a observação participante, desenvolvemos as seguintes atividades:

- Diagnóstico da turma: primeira atividade interventora, foi o diagnóstico mediante uma Prova Brasil do ano 2012 para avaliarmos o nível de alfabetização de cada aluno.

- Festival de brincadeiras: primeiro, as crianças listaram as brincadeiras que conheciam, depois, entrevistaram familiares sobre brincadeiras de infância. Logo após, foram refletir e escrever essas palavras. Formamos um livro coletivo sobre brincadeiras infantis e ao final ocorreu o festival de brincadeiras sobre a escrita de palavras, por meio das brincadeiras do cotidiano das crianças. Sendo assim, fizemos algumas brincadeiras com as crianças e posteriormente, trabalhado a escrita dessas brincadeiras.

- Contação de histórias: contamos as histórias "A velha a fiar" e "Cinderela"; posteriormente, trabalhamos os sons das palavras das histórias. 


\section{Educere "Educare \\ ReVISTA DE EduCAČ̃̃o}

Programa de Pós-Graduação em Educação - Universidade Estadual do Oeste do Paraná

- Identificação de letras e palavras nos textos: na qual demos a cada criança um texto que já havia sido lido por ela e em seguida, falávamos uma palavra do texto para que a partir do som a criança a encontrasse.

- Produção textual: lemos um livro e depois, pedimos para que as crianças recriassem a história sob seu ponto de vista.

Durante as atividades que executamos na escola, procuramos associar, nos alunos participantes da pesquisa, a consciência fonológica discutida por Soares (2018) sobre a sensibilidade sonora da fala. Assim, trabalhamos contações de histórias e atividades escritas, como palavras localizadas nas próprias histórias e as produções textuais, como por exemplo: "Era uma vez uma pequenina fada que vivia com seus amigos, brincando lá perto da casa dela de Barbie ${ }^{\prime \prime}$.

É fundamental que os adultos leiam para as crianças e suscitem a curiosidade. Ao ouvir muitas histórias, dá-se início a aprendizagem para tornarse leitor, e ser leitor é ter um caminho absolutamente infinito de descoberta e de compreensão do mundo (ABRAMOVICH, 2001, p. 16). Desta forma, a contação de histórias possibilitou a imersão das crianças no universo da leitura de uma forma descontraída, bem como na imersão da escrita por meio das produções textuais.

Posteriormente a observação participante, aplicamos questionários abertos com 03 professores dos três primeiros anos do Ensino Fundamental - anos iniciais da escola municipal. De acordo com Gil (2008, p. 121), é uma "técnica de investigação composta por um conjunto de questões que são submetidas a pessoas com o propósito de obter informações". Para Marconi e Lakatos (2003, p. 201), as perguntas que constituem o questionário também "[...] devem ser respondidas por escrito e sem a presença do entrevistador". Assim sendo, o questionário compunha-se por questões abertas sobre idade; sexo; formação, tempo que lecionavam; quantidade de alunos por sala; contribuição das disciplinas da Alfabetização (Linguística Aplicada à Alfabetização e Alfabetização)

Revista Educere Et Educare, Vol. 15, N. 36 (2020) Especial Educere, Out. 2020. Ahead of Print. DOI: $10.17648 /$ educare.v15i36.25716 


\section{Educere Educare \\ ReviSTA De EduCAC̄̃̃o}

Programa de Pós-Graduação em Educação - Universidade Estadual do Oeste do Paraná

e Estágio III durante sua formação inicial; a relação teoria-prática em sala de aula; e as principais dificuldades encontradas durante o processo de alfabetizar.

Deste modo, todos os professores possuíam nível superior em Pedagogia, com experiência de 15 a 32 anos lecionando em sala de aula. Foram escolhidos os docentes das três primeiras séries que se dispuseram a participar da pesquisa. Tendo em vista isso, procuramos entender a realidade de cada participante, levando em consideração a relação que fazem da teoria com a prática, a contribuição das disciplinas voltadas a Alfabetização e as dificuldades que encontraram no processo alfabetizador.

Em seguida, aplicamos os questionários abertos com 08 estudantes do Curso de Pedagogia da UFS que haviam cursado as disciplinas da área de Alfabetização (Linguística Aplicada à Alfabetização ${ }^{2}$ e Alfabetização ${ }^{3}$ e Estágio III ${ }^{4}$, como também se dispuseram a participar da pesquisa. A faixa etária desses alunos foi entre 20 a 40 anos.

Com a finalidade de preservarmos as identidades dos participantes da pesquisa, denominados os estudantes universitários de U1, U2, U3, U4, U5, U6, U7, U8 e os professores, como P1, P2 e P3. Os registros das observações e dos questionários nos permitiram obter informações basilares para composição do presente texto.

\section{RESULTADOS E DISCUSSÃO}

No intuito de atingirmos o objetivo da pesquisa - analisar a relação entre a teoria e a prática na formação em Alfabetização de alunos concludentes do Curso de Pedagogia da UFS e de professores do Ensino Fundamental de uma escola pública localizada no município de São Cristóvão (SE) - indagamos os participantes sobre a contribuição das disciplinas da Alfabetização (Linguística Aplicada à Alfabetização e Alfabetização) e Estágio III durante a formação inicial

Revista Educere Et Educare, Vol. 15, N. 36 (2020) Especial Educere, Out. 2020. Ahead of Print. DOI: $10.17648 /$ educare.v15i36.25716 


\section{Educere Educare \\ ReVISTA DE EDUCACÃ̃o}

Programa de Pós-Graduação em Educação - Universidade Estadual do Oeste do Paraná

de professores; a relação teoria-prática em sala de aula; e as principais dificuldades encontradas durante o processo de alfabetizar. No quadro abaixo, estão elencadas as opiniões dos participantes da pesquisa acerca das disciplinas Linguística Aplicada à Alfabetização, Alfabetização e Estágio III na prática em sala de aula.

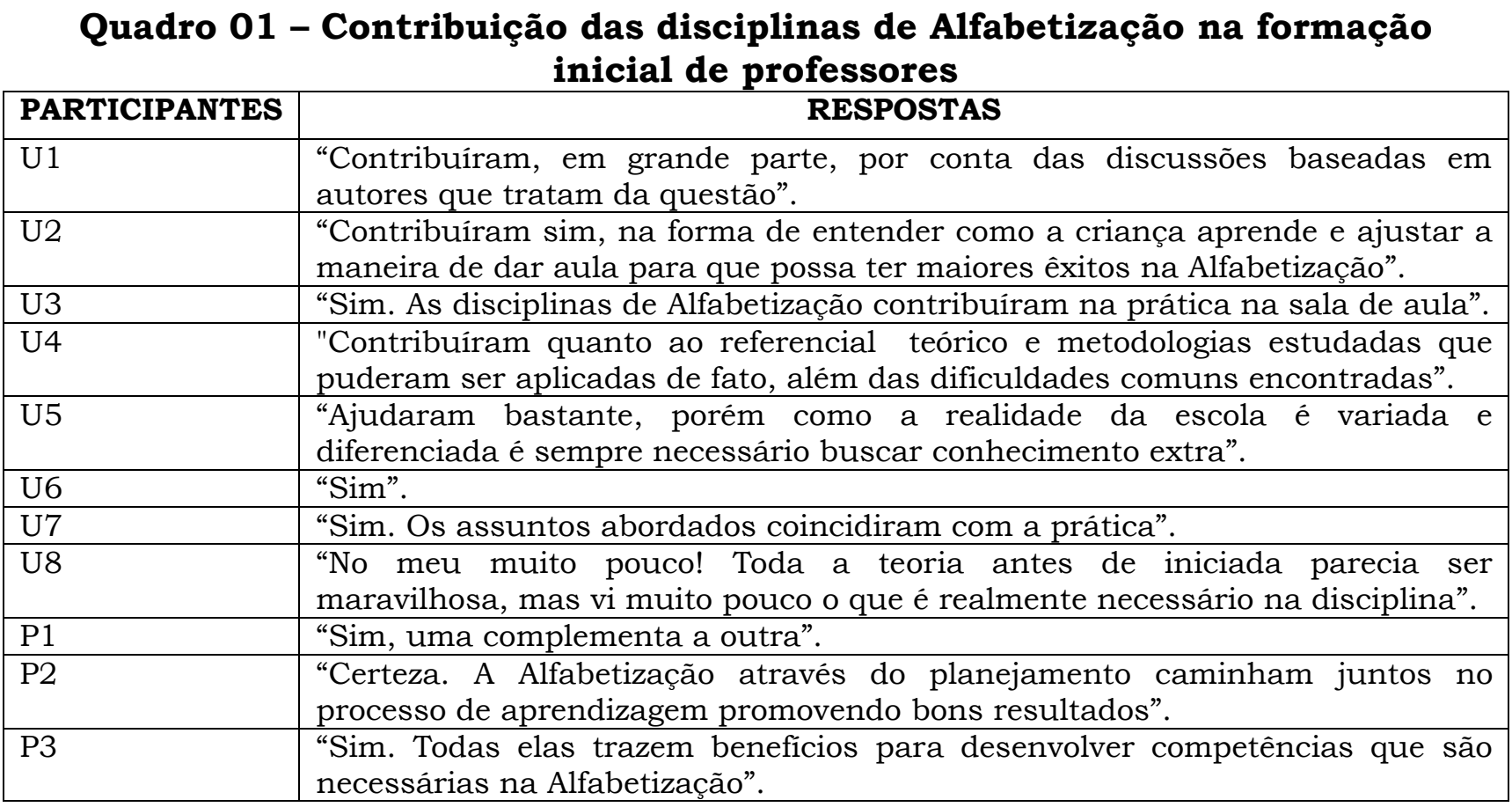

Fonte: Dados coletados pelas pesquisadoras.

No quadro 01, podemos notar que a maioria dos participantes do Curso de Pedagogia da UFS responderam que as disciplinas ajudaram suas práticas. Dessa forma, percebemos que a teoria auxiliou os alunos durante a formação inicial do Curso de Pedagogia a entenderem como as crianças aprendem e como adequar e empregar uma metodologia de ensino de acordo com os objetivos de aprendizagem e as especificidades das crianças. Contribuíram, também, no direcionamento da prática de ensino para o que deve ser entendido e aprendido pelo aluno, como afirmam Fernandes e Souza (2018, p. 11): “os professores precisam estar atentos ainda à melhor forma de alfabetizar para não transformar suas práticas num montante de métodos vazios e sem significado”.

Revista Educere Et Educare, Vol. 15, N. 36 (2020) Especial Educere, Out. 2020. Ahead of Print. DOI: $10.17648 /$ educare.v15i36.25716 


\section{Educere Educare \\ ReVISTA DE EduCACÃ̃o}

Programa de Pós-Graduação em Educação - Universidade Estadual do Oeste do Paraná

Analisamos que os estudantes aplicaram seus conhecimentos teóricos na prática de forma a promover resultados satisfatórios ao aprendizado das crianças, trabalhando os níveis de cada um e buscando outros saberes, além da formação recebida no Curso para melhorar o trabalho com as crianças. Além disso, notamos que os graduandos valorizaram os aprendizados direcionados à aquisição do conhecimento como as fases de desenvolvimento da aprendizagem discutidas Soares (2018); Cagliari (2009) e Abramovich (2001). Com isso, identificamos que os alunos planejaram e adotaram métodos relacionando alguns dos autores que foram abordados durante a formação no Curso de Pedagogia da UFS com a prática vivenciada.

A teoria é fundamental para a prática docente, tendo em vista que o professor precisa saber como trabalhar as especificidades de seus alunos em sala de aula. Sendo assim, a teoria auxilia o processo de identificação para saber o nível de aprendizagem visando desenvolver no aluno as habilidades que ainda não dominam ou o que tem dificuldade. Colello (2001, p.04) destaca que cabe ao professor despertar interesses, "[...] fomentar a atitude reflexiva, apoiar o desenvolvimento, estimular o ambiente rico em experiência ou interações e promover a ação pedagógica facilitadora para elaboração de novas ideias, concepções e hipóteses".

E para isso, o professor necessita de uma boa formação inicial e continuada a fim de desempenhar um bom trabalho. No entanto, os dados revelaram que apenas um dos participantes afirmou que as disciplinas não auxiliaram a prática em sala de aula. Isso denota que nem sempre os conhecimentos acadêmicos serão assimilados na prática, como declara Antunes (2013, p. 377),

O distanciamento e o desconhecimento sobre as histórias de vida dos professores podem explicar, em certa medida, os motivos que os levam a participarem de cursos e seminários sem conseguirem, na maioria das vezes, articular esses conhecimentos na sua sala de aula. Os conhecimentos transmitidos carecem de sentido e de intensidade para provocar questionamentos e reflexões sobre a prática docente.

Revista Educere Et Educare, Vol. 15, N. 36 (2020) Especial Educere, Out. 2020. Ahead of Print. DOI: $10.17648 /$ educare.v15i36.25716 


\section{Educere "Educare \\ Revista de EduCAČ̃̃o}

Programa de Pós-Graduação em Educação - Universidade Estadual do Oeste do Paraná

Deste modo, o conhecimento adquirido durante e após a formação docente deve ser construído e reconstruído em cada realidade, atentando ao domínio da teoria como fundamental nesse processo. Ao fazermos as observações na escola, notamos que alguns professores persistiam em ensinar a ler e a escrever da forma como (aprenderam na escola) foram alfabetizados. Segundo Antunes (2013, p. 377), "[...] é muito comum encontrar professores que acabam esperando dos outros as respostas que de certa forma conhecem, mas em cujo valor não acredita". Com isso, visualizamos que nem sempre a teoria, aprendida em sala de aula, é transformada pelo aluno e posta em prática de acordo com a realidade vivenciada.

Quadro 02 - Relação teoria-prática em sala de aula

\begin{tabular}{|l|l|}
\hline PARTICIPANTES & \multicolumn{1}{|c|}{ RESPOSTAS } \\
\hline U1 & $\begin{array}{l}\text { "Construindo e reconstruindo constantemente conhecimentos e práticas } \\
\text { trabalhadas através das práxis pedagógica". }\end{array}$ \\
\hline U2 & $\begin{array}{l}\text { "Eutantento compreender a teoria e identificar como posso aplicar na prática". } \\
\text { U3 }\end{array}$ \\
\hline U4 & $\begin{array}{l}\text { "Sempre analiso o que diz a BNCC antes de montar um plano de aula ou pôr } \\
\text { "Utilizando dos textos e pesquisas para aplicação na sala de aula através de } \\
\text { suporte teórico". }\end{array}$ \\
\hline U5 & $\begin{array}{l}\text { "Fazemos brincadeiras usando ilustrações, desenhos e colagem com figuras } \\
\text { do alfabeto, números, objetos". }\end{array}$ \\
\hline U6 & $\begin{array}{l}\text { "Articulando a necessidade da turma com a teoria vista na UFS". } \\
\text { U7 }\end{array} \quad \begin{array}{l}\text { "A teoria é tudo que vimos durante o curso. E a prática se aprende na sala de } \\
\text { aula junto aos alunos". }\end{array}$ \\
\hline U8 & $\begin{array}{l}\text { "Utravés de práticas de leitura e material concreto". } \\
\text { alunos seja no coletivo ou individual". }\end{array}$ \\
\hline P1 & P2
\end{tabular}

Fonte: Dados coletados pelas pesquisadoras.

No quadro 02, os estudantes do Curso de Pedagogia da UFS alegaram fazer relação da teoria com a prática em sala de aula. Empregavam a teoria proporcionando ao aluno a construção e o sentido no aprendizado. Já os professores, utilizavam atividades com leitura, uso de livros e matérias que 


\section{Educere "Educare \\ Revista de EduCaç̃̃o}

Programa de Pós-Graduação em Educação - Universidade Estadual do Oeste do Paraná

consideravam pertinentes ao aprendizado dos alunos, no cotidiano escolar. Conforme Candau (2011, p.02),

[...] a educação é vista fundamentalmente como um processo de crescimento pessoal, interpessoal e grupal, e o educador é o facilitador deste crescimento. $O$ processo de formação tem como principal preocupação a aquisição daquelas atitudes necessárias para a mobilização da dinâmica de "tornar-se pessoa", para liberar a capacidade humana de autoaprendizagem de forma que seja possivel o desenvolvimento pessoal "pleno", tanto intelectual quanto emocional.

Sendo assim, a relação que os alunos do Curso de Pedagogia da UFS e os professores faziam da teoria com a prática refletiu, justamente, nesse crescimento pessoal e interpessoal relacionado ao papel do professor como facilitador. O uso dessa relação permitiu que o professor tivesse confiança e autonomia para desempenhar suas práticas conforme sua realidade.

Quadro 03: Principais dificuldades na alfabetização das crianças

\begin{tabular}{|c|c|}
\hline PARTICIPANTES & RESPOSTAS \\
\hline U1 & "Desrespeito". \\
\hline $\mathrm{U} 2$ & $\begin{array}{l}\text { "Indisciplina, desestímulo, falta de comunicação entre família, gestores e } \\
\text { professores". }\end{array}$ \\
\hline U3 & "Falta de recursos e apoio tanto da instituição escola quanto família". \\
\hline $\mathrm{U} 4$ & "Falta de apoio de outros professores". \\
\hline U5 & $\begin{array}{l}\text { "As maiores dificuldades ocorrem geralmente com crianças com algum tipo de } \\
\text { deficiência, no entanto para mim essa dificuldade poderia ser sanada se a } \\
\text { disciplina de Educação Inclusiva ocorresse antes da realização dos Estágios". }\end{array}$ \\
\hline U6 & $\begin{array}{l}\text { "Entender a turma, envolve-los nas explicações porque crianças mais novas } \\
\text { perdem a concentração muito rápido então é necessário ser bem lúdico e } \\
\text { trazer coisas do dia de forma que envolva as crianças da melhor maneira } \\
\text { possivel". }\end{array}$ \\
\hline $\mathrm{U} 7$ & "A quantidade de alunos em sala de aula". \\
\hline U8 & "Não conhecer as vogais e escrever o próprio nome". \\
\hline $\mathrm{P} 1$ & $\begin{array}{l}\text { "[...] a disciplina e limites que a maioria não tem, o comportamento dificulta } \\
\text { bastante". }\end{array}$ \\
\hline P2 & "Leitura, e o reconhecimento das letras do alfabeto, junção de sílabas". \\
\hline P3 & $\begin{array}{l}\text { "Quando a criança chega do pré-escolar sem conseguir ser alfabetizado não } \\
\text { conseguiu aprender fazer o seu nome e não sabe ler palavras simples. O } \\
\text { trabalho do professor do } 1^{\circ} \text { ano redobra". }\end{array}$ \\
\hline
\end{tabular}

Fonte: Dados colhidos pela pesquisadora.

Revista Educere Et Educare, Vol. 15, N. 36 (2020) Especial Educere, Out. 2020. Ahead of Print. DOI: $10.17648 /$ educare.v15i36.25716 


\section{Educere" Educare \\ RevisTa de EduCAC̄̃o}

Programa de Pós-Graduação em Educação - Universidade Estadual do Oeste do Paraná

Os dados elencados no quadro 03 revelaram que a maioria das dificuldades no processo de alfabetizar refere-se ao comportamento indisciplinado e a falta de apoio familiar ou escolar. Nesse ínterim, a falta de apoio (seja da família ou da equipe da própria escola) implica em alunos desinteressados e desanimados. Paralelo a isso, têm-se os fatores socioeconômicos ${ }^{5}$, como a baixa renda familiar. A disparidade social enfrentada por inúmeras famílias influencia diretamente no processo de aprendizagem, uma vez que a maioria do alunado desloca-se até à escola com carência alimentar, prejudicando a sua concentração.

A relação família-escola é imprescindível no processo de alfabetização, haja vista que a família é a base dos primeiros aprendizados. Para Colello (2001, p. $01)$, na escola "[...] o ensino da língua escrita aparece estritamente vinculado à vida estudantil: ler para aprender e escrever para comprovar o aprendizado". Sendo assim, não é difícil visualizar que questões relacionadas ao estudo, para muitas famílias, só devem ser tratadas na escola.

Outro problema mencionado nos relatos aponta para o desconhecimento das letras pelos alunos e por não conseguirem ler. No processo de alfabetização isso é natural, porém, no $3^{\circ}$ Ano do Ensino Fundamental - Anos Iniciais é preocupante. De acordo com Brito (2007), o professor entra em estado de ansiedade por não saber como agir diante de determinadas dificuldades dos alunos.

Ante aos diferentes entraves, o processo de alfabetização precisa ser repensado na prática, pois alguns docentes acabam por fazer seu trabalho desvinculado, isto é, o processo que deveria ser contínuo acaba sendo fragmentado. Assim, o diálogo e o apoio entre os professores e todos os envolvidos com o processo de alfabetização na escola e nas diferentes instâncias municipal, estadual e federal são fundamentais para o desenvolvimento do aluno, pois o docente saberá trabalhar o que ele tem dificuldade ou ainda não aprendeu. 


\section{Educere Educare \\ ReVISTA DE EduCAČ̃̃o}

Programa de Pós-Graduação em Educação - Universidade Estadual do Oeste do Paraná

A presença de alunos com deficiência no ensino regular, disciplina sobre inclusão anteriormente aos estágios e, quantidade de alunos por sala também configuraram como desafios no processo de alfabetização. Diante disso, verificamos que a disciplina Educação Inclusiva é ofertada apenas no $9^{\circ}$ período, no currículo do Curso de Pedagogia da UFS. Tal fator demonstra a fragilidade na formação dos futuros professores, uma vez que os estágios supervisionados se iniciam, somente, a partir do $6^{\circ}$ período. A Lei de Diretrizes e Bases da Educação Nacional (LDB), no 9.394/96, no art. 58º, classifica a Educação Especial como uma modalidade do ensino regular, oportunizando a todas as pessoas com deficiência serem incluídas nas salas de aulas comuns, em qualquer nível educacional. Logo, caso a disciplina fosse ofertada no início dos estágios, corroboraria com o aprendizado prático.

No processo de alfabetização, trabalhar com mais de 20 crianças em uma sala de aula é dificil, pois cada aluno tem suas especificidades e seu nivel de aprendizagem. Por isso, às vezes, esse processo não é desempenhado de forma eficiente por fatores que vão além do domínio do professor. Conforme Pinheiro, Fernandes e Souza (2018, p. 07), "é dificil para um educador preparar e ministrar aula para mais de 15 crianças em estágio de alfabetização, cada uma em diferente nivel de aprendizagem".

A atitude do professor e as metodologias que utilizará depende do nível de conhecimento teórico e da aprendizagem da língua do alfabetizando. No caso da criança que ainda não identifica as letras e não sabe escrever o nome, o processo está no início e o professor deve começar a desenvolver na criança a consciência fonológica, ligada aos sons da oralidade. Desse modo, as crianças vão aprendendo a ler e a escrever palavras, reconhecendo-as na leitura e depois, grafando-as na escrita. Conforme Soares (2018, p. 166-167),

[...] a consciência fonológica é a capacidade de focalizar o som das palavras, dissociando-as do seu significado e de segmentar as palavras nos sons que as continuem. [...] para compreender o princípio alfabético, desenvolva sensibilidade para a cadeia sonora da fala e reconhecimento

Revista Educere Et Educare, Vol. 15, N. 36 (2020) Especial Educere, Out. 2020. Ahead of Print. DOI: $10.17648 /$ educare.v15i36.25716 


\section{Educere "Educare \\ ReVISTA DE EduCAČ̃̃o}

Programa de Pós-Graduação em Educação - Universidade Estadual do Oeste do Paraná

das possibilidades de sua segmentação - desenvolva consciência fonológica.

O processo de alfabetização, como já mencionamos, deve ser dinâmico. A criança precisa desenvolver o aprendizado de forma ativa, pois, "o domínio de uma língua, repito, é o resultado de práticas efetiva, significativas, contextualizadas" (POSSENTI, 1996, p. 47). E o professor precisa ter discernimento de que as crianças possuem conhecimentos prévios que devem ser levados em consideração, sem deixar de apresentar novos saberes (CAGLIARI, 2009).

Nessa perspectiva, a partir dos dados obtidos pudemos perceber as implicações das disciplinas de Alfabetização na formação inicial de professores, os quais relacionavam os fundamentos teóricos à prática escolar. Todavia, algumas dificuldades na alfabetização das crianças foram ressaltadas.

\section{CONSIDERAÇÕES FINAIS}

Ao analisarmos os dados coletados, por meio de questionários abertos e da observação participante, percebemos que os estudantes do Curso de Pedagogia da UFS estabeleceram uma relação direta entre teoria e prática, utilizando metodologias estudadas durante a formação inicial, em sua realidade escolar. Notamos que havia uma preocupação tanto dos estudantes do Curso de Pedagogia da UFS como dos professores em adotar formas descontraídas de aprendizagem, visando ao desenvolvimento no ensino da leitura e da escrita durante o processo de alfabetização.

Além disso, verificamos que a teoria adquirida pelos estudantes do Curso e professores deu-se através das disciplinas Linguística Aplicada à Alfabetização, Alfabetização e Estágio III, as quais contribuíram na forma de planejar as ações de ensino em sala de aula com metodologias, teorias e entendimento sobre a aprendizagem das crianças. Sendo assim, o currículo do Curso de Pedagogia, que

Revista Educere Et Educare, Vol. 15, N. 36 (2020) Especial Educere, Out. 2020. Ahead of Print. DOI: $10.17648 /$ educare.v15i36.25716 


\section{Educere Educare \\ RevisTA De EduCAC̄̃̃o}

Programa de Pós-Graduação em Educação - Universidade Estadual do Oeste do Paraná

está cada vez menos voltado para a educação infantil e para as séries iniciais do ensino fundamental, deve ser revisto, pois percebemos que a teoria ajuda na prática. Os resultados mostraram também que os participantes aplicaram na prática o que estudaram, compreendendo de que maneira seus estudos podiam se encaixar e melhorar o aprendizado de seus alunos. As dificuldades apontadas pelos participantes no processo alfabetizador foram o desrespeito, a indisciplina, o desestímulo, a falta de apoio escolar e familiar, presença de alunos com deficiência, quantidade de alunos por turma e o desconhecimento das letras e da leitura pelos alunos.

Portanto, a Alfabetização se configura como componente basilar na formação inicial de professores para atuação com crianças, jovens e adultos. Aferimos que a formação inicial do Curso de Pedagogia da UFS estabelecia relação direta dos fundamentos teóricos da Alfabetização com a prática escolar.

\section{REFERÊNCIAS BIBLIOGRÁFICAS}

ABRAMOVICH, Fanny. Literatura infantil: gostosuras e bobices. 5. ed. São Paulo: Scipione, 2001.

ANTUNES, Helenise Sangoi. Alfabetização e formação de professores: algumas reflexões sobre a leitura e a escrita. Educação, v.38, n.2, p. 375-387, 2013.

BERTOTTI, Rudimar Gomes; RIETOW, Gisele. Uma breve história da formação docente no brasil: da criação das escolas normais as transformações da ditadura civil-militar. In: XI CONGRESSO NACIONAL DE EDUCAÇÃO- EDUCERE, Paraná: Pontifícia Universidade Católica. 2013.

BRASIL. Ministério da Educação. Instituto Nacional de Estudos e Pesquisas Educacionais Anísio Teixeira. Avaliação nacional de alfabetização 2016. Brasília, DF, 2017. Disponivel em: http:// portal.inep.gov.br. Acesso em: 26 mar. 2020.

BRASIL. Lei n ${ }^{\circ} 9.394$ de 20 de dezembro de 1996. Estabelece as diretrizes e bases da educação nacional. Diário Oficial da União, 23 dez. 1996.

Revista Educere Et Educare, Vol. 15, N. 36 (2020) Especial Educere, Out. 2020. Ahead of Print. DOI: $10.17648 /$ educare.v15i36.25716 


\section{Educere "Educare \\ ReVISTA DE EduCAČ̃̃o}

Programa de Pós-Graduação em Educação - Universidade Estadual do Oeste do Paraná

BRITO, Antónia Edna. Prática pedagógica alfabetizadora: a aquisição da língua escrita como processo sociocultural. Revista Ibero-americana de Educación, v.44, n.4, p.12-20, 2007.

CAGLIARI, Luiz Carlos. Alfabetização e linguística. 11. ed. São Paulo: Scipione, 2009.

CANDAU, Vera Maria Ferrão. A formação de educadores: uma perspectiva multidimensional. Em aberto, v. 1, n. 8, 2011.

COLELLO, Silva M. Gasparian. Alfabetização: do conceito à prática pedagógica. Identidades e saberes - Novas perspectivas em educação, 2001.

DIOGO, Emilli Moreira; GORETTE, Milena da Silva. Letramento e alfabetização: uma prática pedagógica de qualidade. In: X CONGRESSO NACIONAL DE EDUCAÇÃO - EDUCERE, Paraná: Pontifícia Universidade Católica. 2011.

FERNANDES, Priscila Dantas; SOUZA, Verônica dos Reis Mariano. O ensino da leitura e da escrita: desafios do PNAIC. Revista Contemporânea de Educação, v. 13 , n. 28, p. 611-630.

FERNANDES, Priscila Dantas; SOUZA, Verônica dos Reis Mariano. O Pacto Nacional pela Alfabetização na Idade Certa: em foco, o eixo Língua Portuguesa. In: ALVES, Fábio; SOBRAL, Maria Neide. Memórias de alfabetizadorasformadoras (Org.). Aracaju: UFSE; Assis: Seike \& Monteiro, 2019. p. 303-330.

FREIRE, Paulo. Pedagogia da Autonomia: saberes necessários a prática educativa. São Paulo: Paz e Terra, 1996.

GIL, Antonio Carlos. Métodos e técnicas de pesquisa social. 6. ed. São Paulo: Atlas, 2008.

GOMES, M. O.; LIMA, M. S. L. Redimensionando o papel dos profissionais da Educação: algumas considerações. In: PIMENTA, S. G.; GHEDIN, E. (Orgs.). Professor reflexivo no Brasil: gênese e crítica de um conceito. São Paulo: Cortez, 2005.

MARCONI, Marina de Andrade; LAKATOS, Eva Maria. Fundamentos de metodologia científica. 5. ed. São Paulo: Atlas, 2003.

MINISTÉRIO DA EDUCAÇÃO. Conselho Nacional de Educação. Resolução CNE/CP no 1, de 15 de maio de 2006. Institui Diretrizes Curriculares Nacionais para o Curso de Graduação em Pedagogia, licenciatura. Diário Oficial [da] União, Seção 1 - 16/05/2006, - Brasília, DF, 16 de mai. 2006.

Revista Educere Et Educare, Vol. 15, N. 36 (2020) Especial Educere, Out. 2020. Ahead of Print. DOI: $10.17648 /$ educare.v15i36.25716 


\section{Educere "Educare \\ ReVISTA DE EduCACÃ̃o}

Programa de Pós-Graduação em Educação - Universidade Estadual do Oeste do Paraná

MINISTÉRIO DA EDUCAÇÃO. Conselho Nacional de Educação. Resolução no 2, de 1 o de julho de 2015. Define as Diretrizes Curriculares Nacionais para a formação inicial em nível superior (cursos de licenciatura, cursos de formação pedagógica para graduados e cursos de segunda licenciatura) e para a formação continuada. Diário Oficial [da] União, Brasília, 2 de julho de 2015 - Seção 1 - pp. $8-12$.

MORAES, Artur Gomes de; LEITE, Tania Maria S.B. Rios; SÁ, Carolina Figueiredo de; PESSOA, Ana Cláudia R. Gonçalves. Apropriação do sistema de escrita alfabética pelas crianças: Que caminhos percorrem? Como podemos auxiliá-las em suas trajetórias de aprendizagem? In: Pacto Nacional pela Alfabetização na idade certa: apropriação do sistema de escrita alfabética e a consolidação do processo em alfabetização em escolas do campo: Educação do campo. Unidade 03/ Ministério da Educação, Secretaria de Educação Básica, Diretoria de Apoio à Gestão Educacional. Brasília: MEC, SEB, 2012. p. 59.

NÓVOA, António. Profissão Professor. 2. ed. Porto: Porto Editora, 1995.

PINHEIRO, Tauam Marques; FERNANDES, Priscila Dantas; SOUZA, Verônica dos Reis Mariano. Desafios dos professores no ensino de Língua Portuguesa:

formações do PNAIC. In: 11 o Encontro Internacional de Formação de Professores/12o Fórum Permanente de Inovação Educacional, 2018, Aracaju. Anais do 11o Encontro Internacional de Formação de Professores/12o Fórum Permanente de Inovação Educacional, 2018.

POSSENTI, Sírio. Por que (não) ensinar gramática na escola. Sírio Possenti Campinas, SP: ALB: Mercado de Letras, 1996. (Coleção Leituras no Brasil).

POERSCH, José Marcelino. Suportes linguísticos para a alfabetização. 2. ed. Porto Alegre: Sagra, 1990.

SOARES, Magda. Alfabetização: a questão dos métodos. São Paulo: Contexto, 2018.

SOARES, Magda. Letramento: um tema em três gêneros. 3. ed. Belo Horizonte: Autêntica, 2012.

SOUZA, Verônica dos Reis Mariano. Linguística aplicada à alfabetização (lecture, Universidade Federal de Sergipe, São Cristóvão/SE, 2019).

TRIVIÑOS, Augusto Nibaldo Silva. Introdução à pesquisa em ciências sociais: a pesquisa qualitativa em educação. São Paulo: Atlas, 2009.

Revista Educere Et Educare, Vol. 15, N. 36 (2020) Especial Educere, Out. 2020. Ahead of Print. DOI: $10.17648 /$ educare.v15i36.25716 


\section{Educere Educare \\ ReVISTA DE EDUCACÃO}

Programa de Pós-Graduação em Educação - Universidade Estadual do Oeste do Paraná

VIRAGO, Carine Ferreira Machado. Políticas públicas de alfabetização - pacto nacional de alfabetização na idade certa (pnaic) - da teoria à prática. Fórum Internacional de Pedagogia, Rio Grande do Sul, jul/ago, 2014.

\section{Notas:}

${ }^{1}$ Exemplo de escrita textual de um aluno do $3^{\circ}$ ano do Ensino Fundamental, participante da pesquisa.

2 Disciplina ofertada no $3^{\circ}$ periodo do Curso de Pedagogia da UFS. Aborda a concepção de linguagem e de alfabetização; variação linguística e fundamentos linguísticos da alfabetização; significação e contextualização; função social e política da alfabetização.

${ }^{3}$ Disciplina ofertada no $4^{\circ}$ período do Curso de Pedagogia da UFS. Aborda o processo de aquisição da leitura e escrita pela criança; aquisição da linguagem pela criança surda; letramento e alfabetização; métodos de alfabetização; análise de cartilhas e de textos espontâneos produzidos pela criança; levantamento e análise de experiências alternativas.

4 Disciplina ofertada no $7^{\circ}$ periodo do Curso de Pedagogia da UFS. Aborda planejamento/execução/avaliação de atividades de docência nos anos iniciais do Ensino Fundamental; registro; análise; relatório.

${ }^{5}$ Esses dados foram obtidos mediante diálogos informais com a diretora da escola, os professores e as crianças.

Recebido em: 29-08-2020

Aceito em: 06-10-2020 